\title{
Alfabetização, saneamento e regeneração nas iniciativas de difusão da escola primária em São Paulo
}

\author{
Heloisa Helena Pimenta Rocha
}

Resumo: No âmbito das intervenções desenhadas, a partir da década de 1920, a educação e a saúde passaram a configurar-se como pilares da obra de redenção do povo da suposta ignorância e da doença e, na mesma medida, da obra de regeneração da nação. Este artigo analisa o projeto de educação higiênica por meio do qual se buscou incutir nas crianças um conjunto de hábitos articulados em torno do objetivo de formação de um ideal de homem forte, saudável, produtivo e ordeiro. Recortam-se iniciativas capitaneadas pelos grupos investidos nos altos cargos da instrução pública em São Paulo, atentando para as leituras que fazem dos problemas sociais, o lugar que conferem à educação e à saúde em seus diagnósticos e nas propostas que formulam. Tomam-se como fontes manuais escolares de higiene produzidos para a escola primária, procurando apreender as marcas desse projeto, por intermédio de uma interrogação que visa flagrar as prescrições higiênicas, em suas articulações com as imagens que esses impressos põem em circulação.

Palavras-chave: História da educação; manuais escolares; higienismo.

\section{Literacy, hygienism and regeneration in initiatives for spreading the elementary school in São Paulo}

Abstract: In the context of the interventions designed since the 1920s, education and health have been shaped up as pillars of the work of redeeming the Brazilian population from the supposed ignorance and disease, and thus regenerating the nation. This paper examines the hygienic education project, which sought to instill in children a set of habits articulated around the goal of forming an ideal of man who would be strong, healthy, productive and disciplined This study analyzes these initiatives led by the public education policy and decision makers from the state of Sao Paulo, considering their understanding of the social issues and the place assigned to education and health in their diagnoses, proposals and policies. For such, this study used the hygiene textbooks produced for the elementary school as references, seeking to grasp and question the hygienic prescriptions made by the policy makers in connection with the images these printed materials proposed.

Key words: history of education; textbooks; hygienism.

Professora do Departamento de Educação, Conhecimento, Linguagem e Arte (Delart) da Faculdade de Educação da Unicamp, Campinas, SP, Brasil. Bolsista de produtividade em pesquisa do CNPq e pesquisadora associada do Centro de Investigación MANES (UNED/Madri). heloisah@unicamp.br 
A educação do povo foi representada, desde a primeira metade do século XIX, como possibilidade de manutenção da ordem e como meio de inserção do Brasil no circuito das nações consideradas civilizadas, embora caiba lembrar que o termo povo recobriu historicamente diferentes sentidos, servindo para designar grupos sociais que não podem ser tomados como homogêneos. Nesse sentido, os intentos de constituição de uma nação moderna encontraram na educação do povo um dos seus mais importantes pilares, produzindo-se a crença de que era possível atuar, por meio da educação, sobre amplos contingentes da população, representados sob os signos da ignorância e do atraso. No âmbito dessas reflexóes, a temática da configuração racial de uma nação constituída por diferentes grupos étnicos e herdeira de uma tradição escravista não se apresentou como uma questão menor, ganhando destaque no período de transição entre os séculos XIX e XX.

Recorrente no discurso das elites ilustradas brasileiras desde o século XIX, a discussão sobre a educação do povo sofreu, a partir da década de 1920, uma sutil inflexão, articulando-se aos intentos de conter os supostos riscos de degenerescência racial. Intentos esses que se fundavam em uma "aposta otimista na natureza infantil e na educabilidade da criança” (Carvalho, 1997, p. 279), a qual respondeu pela gradativa corrosão das representações cientificistas, em cuja formulação a degenerescência foi configurada como limite inexorável das intenções pedagógicas, como assinalam as análises de Carvalho sobre as mutações do discurso pedagógico no período.

Inflexão semelhante pode ser observada nas iniciativas de reforma dos serviços de saúde capitaneadas nos anos 1920. Reformas essas que, a par da relativização das teorias racistas, amplamente difundidas desde o século XIX, calcaram-se na crença na possibilidade de redenção do homem brasileiro, por meio de intervençóes em que a preservação da saúde somente se mostrava possível quando articulada a medidas educativas ${ }^{1}$.

Nesse movimento, educação e saúde passaram a ser concebidas como questões indissociáveis, configurando-se como pilares da obra de redenção do povo da suposta ignorância e da doença e, nessa medida, de regeneração da nação. Pensada como parte de um amplo projeto de reforma dos costumes, a educação do povo passou a ser vista como meio de formação de hábitos de vida saudáveis, articulados em torno do objetivo de constituição do brasileiro como um homem forte, saudável, produtivo, trabalhador e ordeiro ${ }^{2}$.

I Exemplar, nesse sentido, foi a reforma sanitária conduzida por Geraldo Horácio de Paula Souza em São Paulo, em 1925, que elegeu como elemento central a educação sanitária como meio de formação da consciência sanitária da população. Reforma que, segundo sugere Ribeiro (1993) pode ser traduzida por meio da fórmula: “Dai educação a quem tem fome!”. A esse respeito, cf. também Rocha (2003b).

2 Tais articulações podem ser observadas nas discussões que tiveram lugar nas conferências promovidas pela Associação Brasileira de Educação, na década de 1920. Entidade essa que 
Neste artigo, procura-se analisar o projeto de educação higiênica, por meio do qual se buscou incutir nas crianças, desde a mais tenra idade, um conjunto de hábitos capazes de, a um só tempo, redimir o povo da suposta ignorância, anomia, doença, e libertar o país da pecha que o identificava a um "enorme hospital"'. Recortam-se, de modo mais específico, algumas iniciativas capitaneadas pelos grupos investidos nos altos cargos da instrução pública em São Paulo, nas primeiras décadas do século XX, procurando-se nuançar as leituras que fazem dos problemas sociais, bem como o lugar que conferem à educação e à saúde em seus diagnósticos e nos projetos que formulam para o enfrentamento dos problemas identificados em São Paulo. Problemas esses tomados, nas leituras que esses educadores fazem dos problemas sociais de seu tempo e nos diagnósticos dos dilemas que identificam, como questōes inadiáveis, cuja abrangência exigia soluçôes que não podiam restringir-se ao estado de São Paulo.

$\mathrm{Na}$ análise dessas iniciativas, tomam-se como fontes manuais escolares de higiene produzidos para a escola primária, em cuja leitura se procura apreender as marcas desse projeto de constituição do homem brasileiro, por intermédio de uma interrogação que visa flagrar as prescrições higiênicas, em suas articulações com as imagens que esses impressos põem em circulação. Examinam-se também os Anuários do Ensino do Estado de São Paulo, procurando captar os modos como as questôes educacionais, em sua interface com as questôes de saúde, são tematizadas por alguns dos nomes que estiveram à frente da Diretoria Geral da Instrução Pública ${ }^{4}$.

\section{maior mal do Brasil contemporâneo}

Em 1918, Oscar Thompson, diretor geral da Instrução Pública do estado de São Paulo, alarmado com o elevado número de crianças entre 7 e 12 anos que não

aspirava a converter-se em fórum privilegiado para a discussão das questões educacionais em nível nacional, assumindo, como eixo das suas propostas, as questões referentes à higiene, à moral e ao trabalho, como assinala Carvalho (1998).

3 Alusão à máxima do médico Miguel Pereira que, em 1916, sentenciava: "o Brasil é um vasto hospital”; afirmação que se tornaria recorrente, no período, nas discussões sobre as questões sanitárias e suas consequências para o progresso do país. Indícios da sua presença no discurso dos educadores podem ser observados no relatório apresentado pelo inspetor escolar Benedicto Tolosa ao diretor geral da Instrução Pública, em 19 | 8: "'O Brasil é um vasto hospital', disse, com justeza, algum indivíduo pessimista. Acrescentamos nós, com tristeza: 'um vasto hospital sem médicos nem enfermeiros'” (Annuario do Ensino do Estado de São Paulo, 1918, p. 748).

$4 \quad \bigcirc$ artigo apresenta resultados parciais dos projetos de pesquisa "Biblioteca de Higiene para as crianças e seus mestres: produção, circulação e usos de manuais escolares" (CNPq/Bolsa de Produtividade em Pesquisa) e "Manuais escolares de Higiene: produção, circulação e recomendações de usos" (CNPq/Edital Universal/2009). Uma versão preliminar dessa discussão foi apresentada, em colaboração com a doutoranda Maria das Graças Sandi Magalhães, na 3 I $^{\text {a }}$. Sessão da International Standing Conference for the History of Education, em agosto de 2009 , na Universidade de Utrecht (Holanda), com apoio da Fapesp e do Faepex/Unicamp.

Pro-Posições, Campinas, v. 22, n. 2 (65), p. 151-172, maio/ago. 2011 
frequentavam escolas públicas ou particulares, dispôs-se a traçar um plano, com vistas à extinção do analfabetismo no estado ${ }^{5}$. O problema mostrava-se tanto mais grave quando se considerava que, de um total de aproximadamente 500 crianças nessa faixa etária, residentes nas zonas rurais ou nas regiōes mais afastadas dos centros urbanos, um percentual que ultrapassava os $50 \%$ estava fora da escola. Em suas ponderações, a autoridade considerava a urgência da difusão do ensino primário às populações residentes nos mais distantes rincôes do estado, uma vez que, segundo alertava, era o futuro da nação que se encontrava em jogo. Tais preocupações evidenciam-se na indagação que percorre o relatório apresentado naquele ano ao secretário do Interior, Oscar Rodrigues Alves, expressa nos seguintes termos: "que fazer para educar esses milhares de menores, que crescendo analfabetos, constituirão elementos negativos do nosso progresso?" (Annuario do Ensino do Estado de São Paulo, 1918, p. 12).

Segundo as análises de Thompson, os benefícios advindos das medidas voltadas para o enfrentamento da questão não se restringiriam a São Paulo, podendo as iniciativas implantadas nesse estado contribuir, de modo decisivo, para a solução dos inúmeros problemas decorrentes do analfabetismo em todo o país, incluindo-se entre eles os de ordem econômica, já que, conforme ressaltava,

a escola aumenta a capacidade produtiva da nação; a escola desperta as forças latentes de um povo; a escola, enfim, num país novo e de população heterogênea, como o nosso, funde todas as nacionalidades, dando-nos um povo único, coeso e com as mesmas aspirações. Na escola, enfim, está a nossa grandeza futura, sob todos os pontos de vista.? (Ibidem, p. 19)

Proposições em relação ao papel da escola no progresso das nações já estavam presentes no relatório apresentado por Thompson em 1910, quando de sua primeira passagem pela Diretoria Geral da Instrução Pública. Naquele momento, tematizando o papel dos métodos de ensino ativos na aquisição dos conhecimentos, ele afirmava a importância da escola no desenvolvimento das capacidades físicas e psíquicas dos indivíduos e, por essa via, no desenvolvimento das nações:

5 Oscar Thompson foi diretor da Escola Normal da Praça de 1901 a 1920, respondendo pela Diretoria Geral da Instrução Pública em duas gestões: a primeira, no período entre 1909 e | 9 | I ; e, posteriormente, de 1917 a 1920, quando foi substituído por Antônio de Sampaio Dória.

6 Conforme os dados apresentados por Thompson, em relação ao ano de 1918, a população em idade escolar (7 a 12 anos) atingiu, no estado de São Paulo, a cifra de 480. 164 crianças, dentre as quais apenas 232.62 I frequentavam as instituições de ensino primário, permanecendo as restantes 247.543 sem escolas. A população do estado estimada naquele ano era de aproximadamente 3.800.000 habitantes (Anuário do Ensino, 1918).

7 Optou-se, neste texto, pela atualização da ortografia das citações extraídas dos documentos pesquisados. 
é incontestável que todos os países civilizados procuram aperfeiçoar a organização do ensino público, de maneira que a futura geração se apresente melhor preparada na luta pela vida. [...] Educar o homem é, de fato, formá-lo para a vida; prepará-lo física e espiritualmente para o mundo. Aí o sucesso da própria vida depende sempre menos da origem ou da situação pecuniária dos indivíduos, porém de suas qualidades físicas e psíquicas granjeadas ou desenvolvidas na escola. (Annuario do Ensino do Estado de São Paulo, 1909-1910, p. 1)

Decidido a enfrentar um problema de tamanha magnitude, que se traduzia na manutenção de mais da metade da população de 7 a 12 anos distante dos bancos escolares, Thompson solicita que os seus auxiliares e todos os educadores interessados nas questōes ligadas à difusão da escolarização se debrucem sobre o estudo da situação, procurando responder à inquietante indagação: "como extinguir no estado de São Paulo esse número de analfabetos?" (Annuario do Ensino do Estado de São Paulo, 1918, p. 20).

Paralelamente a essa iniciativa, o diretor solicita aos inspetores escolares que se manifestem sobre a situação do ensino primário nas zonas sob sua responsabilidade, abrangendo em suas observaçōes as escolas públicas e particulares. O questionário proposto recobria, entre outros, aspectos ligados a número de classes e escolas, frequência dos alunos, localização das escolas, assistência escolar, programas e horários, além de itens que diziam respeito ao papel da escola na obra do saneamento do Brasil e na preparação do aluno para a vida pública e a defesa da pátria, envolvendo também a questão do voto e do serviço militar obrigatório.

Os relatórios apresentados pelos inspetores identificavam como causas para as deficiências observadas nas escolas: falta de fiscalização por parte das autoridades municipais; insuficiência do quadro de inspetores escolares estaduais, o que redundava na impossibilidade de uma fiscalização mais assídua; descaso dos pais em relação à educação das crianças, que se somava ao estado de extrema pobreza em que viviam; falta de assiduidade, negligência, despreparo e desinteresse por parte dos mestres; precariedade das escolas; insuficiência de vagas; deficiência de matrículas e baixa frequência dos alunos. Não faltaram inspetores que assinalassem como uma das causas que respondiam pelos problemas ligados à matrícula $\mathrm{e}$ à frequência escolares as doenças endêmicas e epidêmicas que assolavam algumas regiōes do estado.

A indagação levantada por Thompson (Annuario do Ensino do Estado de São Paulo, 1918), construída com base nos dados sobre o número de crianças em idade escolar que não frequentavam as escolas primárias naquele momento, projetava um futuro sombrio para o estado, em que os pequenos analfabetos engrossariam 
a massa de adultos analfabetos, comprometendo o progresso nacional ${ }^{8}$. Assim, examinando a realidade presente e avaliando os riscos futuros, alertava Thompson (Ibidem, p. 19):

é, pois, dolorosa a situação dessas crianças, - cidadãos de amanhã -, condenadas ao analfabetismo, e que, dentro em pouco, ultrapassando o período da idade do ensino obrigatório, irão aumentar o número de adultos analfabetos, que mourejam no Estado, sem ambições, indiferentes, de todo em todo, às coisas e homens do Brasil, constituindo-se, assim, outros tantos fatores negativos do nosso progresso.

Dentre as respostas oferecidas à questão, que envolvia a solução daquele que era considerado, à época, o "maior mal do Estado" e "também o maior de todo o Brasil" (Ibidem, p. 19), destaca-se a carta aberta de Sampaio Dória, professor catedrático de Psicologia, Pedagogia e Educação Cívica da Escola Normal Secundária de São Paulo, publicada no Jornal do Comércio (apud Annuario do Ensino do Estado de São Paulo, 1918)'. Em sua intervenção no debate, o educador propõe-se a sugerir algumas medidas que viessem a sanar o problema do analfabetismo sem ampliar os gastos públicos com a educação. Suas análises sobre a situação brasileira tomam como ponto de partida a afirmação dos riscos e dos prejuizos advindos dos elevados indices de analfabetismo, observados em todos os estados, para o progresso do pais, ${ }^{10}$ já que, segundo assinalava Dória (Annuario do Ensino do Estado de São Paulo, 1918, p. 58-59):

8 Debruçando-se sobre o problema das crianças em idade escolar que não frequentavam a escola primária, o diretor não ignorava o fato de que existia no estado um grande contingente de analfabetos adultos e "menores analfabetos", assim considerados os que estavam acima da faixa etária de obrigatoriedade escolar. Sua opção por enfrentar o problema das crianças em idade escolar encontrava justificativa em uma representação da infância que a identificava com o futuro da nação, abarcando essa representação tanto os riscos que ameaçavam o país quanto a promessa de um futuro glorioso: "acentuaremos, desde já, que o nosso estudo em prol da alfabetização não colherá a massa total de analfabetos. [...] abrangerá somente as crianças dos 7 aos 12 anos de idade, isto é, os que são obrigados a frequentar a escola, os que vão constituir a mocidade futura da Pátria, os que, aprendendo a ler, escrever e contar dos 7 aos 12 anos de idade, hão de procurar, como chefes de família, educar melhor a sua prole" (Annuario do Ensino do Estado de São Paulo, 1918, p. 21).

9 Não é demais lembrar que Sampaio Dória e Oscar Thompson integravam o Conselho Deliberativo da Liga Nacionalista de São Paulo, entidade fundada em 1917, em torno dos objetivos de mobilização cívica com vistas ao "soerguimento da nação", tendo como principais bandeiras o voto secreto, o serviço militar obrigatório, o combate ao analfabetismo e a propagação da instrução. No âmbito dessa entidade, Thompson compunha a Comissão de Instrução Popular, enquanto Dória era membro da Comissão de Educação Cívica, não sendo possível, segundo assinala Carvalho, compreender a solicitação de Thompson e a resposta de Dória, sem levar em conta sua militância na liga. (Cf. Carvalho, 1999).

10 Sobre as discussões em torno da questão do analfabetismo no período, ver Carvalho (1998), Nagle (200 I) e Rocha (1995).

Pro-Posiçôes, Campinas, v. 22, n. 2 (65), p. 151-172, maio/ago. 2011 
Hoje, não há quem não reconheça e não proclame a urgência salvadora do ensino elementar às camadas populares. $\mathrm{O}$ maior mal do Brasil contemporâneo é a sua porcentagem assombrosa de analfabetos. [...]

Porque o analfabetismo das massas é incompatível com a civilização mais elementar. [...]

O Brasil, repleto de riquezas latentes, só será realmente uma nação poderosa e triunfante, se os seus Governos primarem no propósito, decisivo e obstinado, de alfabetizar o seu povo, acabrunhado e murcho, numa indiferença que apavora. [...]

A alfabetização do povo é, na paz, a questão nacional por excelência. Só pela solução dela, o Brasil poderá assimilar o estrangeiro que aqui se instala em busca da fortuna esquiva. Do contrário, é o nacional que desaparecerá absorvido pela inteligência mais culta dos imigrantes. Não há fugir ao dilema: ou o Brasil manterá o cetro dos seus destinos, desenvolvendo a cultura dos seus filhos, ou será, dentro de algumas gerações, absorvido pelo estrangeiro, que para ele aflui.

Representado como origem de todos os males e de todos os vícios, elemento que se opunha à civilização, inviabilizando o progresso e pondo em risco a própria segurança nacional, o analfabetismo se impunha como uma questão inadiável, exigindo dos dirigentes uma atuação no sentido de alfabetizar as camadas populares, sobre as quais repousava a pecha de indiferentismo e anomia. A alfabetização representava, nesse sentido, a possibilidade de redenção de um povo considerado "acabrunhado", "murcho" e tomado de uma "indiferença que apavora".

Nas ponderações sobre os modos de enfrentamento do analfabetismo reinante no estado, Dória afirmava que não se deveria perder de vista que cabia à escola primária responder aos objetivos de ensinar a "ler, escrever e contar; assegurar a saúde e o vigor do corpo; saber ver, ouvir e mover-se; ensaiar a imaginação e o raciocínio; começar hábitos de disciplina moral e cívica" (Ibidem, p. 61) . Entretanto, tendo em vista as limitações orçamentárias, propunha uma escola alfabetizante de dois anos, na qual cada série funcionaria em turnos diários de duas horas e meia, priorizando o ensino da leitura, da escrita, do cálculo e de noções gerais de história, geografia, instrução moral e cívica, além de desenho, canto e exercícios físicos. A solução imaginada, que implicava em redução dos anos de escolaridade, implantar-se-ia, em meio a muitas controvérsias, dois anos mais tarde, quando Dória assumiu o comando da Diretoria Geral da Instrução Pública, cargo no qual permaneceu até abril de 1921.

A reforma capitaneada por Dória em 1920 instituiu a escola alfabetizante, reduzindo a escolaridade obrigatória de quatro para dois anos e priorizando, 
por essa via, a difusão da escola às populaçôes marginalizadas ${ }^{11}$, não se devendo esquecer que, além do combate ao analfabetismo, figurava entre os objetivos da reforma coibir as iniciativas de criação de escolas estrangeiras ou escolas ligadas a movimentos como o anarquismo. Ao mesmo tempo, buscou redefinir as bases sobre as quais se assentava a pedagogia, visando ancorá-la na ciência experimental; ampliou a importância conferida ao ensino de higiene no currículo das escolas de formação de professores, considerando ser o professor o elemento central na educação higiênica das crianças, além de reorientar as práticas administrativas, procurando assegurar um maior controle e padronização ${ }^{12}$. O conjunto de medidas adotadas não pode ser entendido sem se levar em conta a militância do reformador em espaços como a Liga Nacionalista de São Paulo, cuja atuação se articulava aos propósitos de moralização e regeneração da população.

Em prol do saneamento ou "O saneamento pela educação"13

Paralelamente às discussões sobre as medidas a serem tomadas com vistas a reduzir o analfabetismo, o Anuário do Ensino de 1918 registra a iniciativa do secretário do Interior, de oferecimento de um curso de higiene pública elementar aos diretores de grupos escolares das zonas rurais, o qual teria lugar no Instituto Butantã, sob a responsabilidade de Vital Brasil. Iniciativa essa que se inseria numa ampla campanha "em prol do saneamento do interior" (Ibidem, p. 212) ${ }^{14}$. No

II O artigo 94 do Decreto 3.356, que regulamentou a Lei I.750, de dezembro de 1920, estabelecia que: "As escolas isoladas passarão a ter um tipo único de dois anos de curso, localizadas pelo Governo de acordo com os núcleos de analfabetos (art. 14 da Lei n. 1.750)". Determinava, ainda, em seu artigo 99, que: "Nos lugares em que for excessiva a matrícula de analfabetos, o Governo poderá desdobrar em dois períodos de 3 horas, as escolas isoladas e as classes de escolas reunidas e grupos escolares (art. I 4 da Lei I .750)" (Annuario do Ensino do Estado de São Paulo, 1920-1921, p. 155). Por esse dispositivo legal, ficavam obrigadas a frequentar a escola primária, conforme dispunha o artigo $9^{\circ}$, as crianças de 9 e 10 anos de idade. Essas orientações foram revogadas em 1925, por meio da Lei 2.095, que estabeleceu o ensino primário de quatro anos nos grupos escolares e de três, nas escolas isoladas e reunidas, instituindo a obrigatoriedade do ensino para as crianças de 7 a 12 anos.

12 Ver, a esse respeito, Carvalho (1999), Antunha (1976) e Nagle (200 I).

13 Alusão ao título da tese defendida por Antonio de Almeida Junior na Faculdade de Medicina de São Paulo em 1922.

I4 O tema do papel da escola no saneamento também esteve presente na lista de questões sobre as quais os inspetores escolares foram chamados a debruçar-se naquele mesmo ano. Em suas manifestações, alguns dos inspetores procuraram realçar o acerto da iniciativa de formação dos diretores, afirmando que a repetição dos preceitos de higiene pelas crianças e sua difusão aos pais acabaria "por impressionar a uns e outros, incutindo-lhes no espírito a necessidade de sua observação. E só assim será lícito esperar para o futuro uma geração mais vigorosa e sadia, enérgica e capaz para os embates da vida" (Annuario do Ensino do Estado de São Paulo, 1918, p. 723). Destacaram, ainda, o papel do professor na tarefa de aproveitar as situações propícias para insinuar nos espíritos "as mais simples regras de higiene - na casa, na roupa, na alimentação e no trabalho, concorrendo assim para a saúde do corpo, fonte incontestada dos prazeres da vida, condição para ulterior desenvolvimento intelectual, que começa com a compreensão da

Pro-Posições, Campinas, v. 22, n. 2 (65), p. 151-172, maio/ago. 2011 
convite dirigido aos diretores, Thompson lembrava o papel da escola e do professor na difusão de conhecimentos de higiene e, por outro lado, a importância desses conhecimentos na melhoria das condições de vida e trabalho da população e, de modo específico, das populações rurais:

Convencido como estou de que a escola e o professor público, são os fatores mais poderosos do nosso progresso em todos os ramos da nossa atividade, espero que, na escola sob vossa direção e no vosso meio, sejais esforçado propagador dos conhecimentos de higiene pública elementar, conhecimentos esses que hão de concorrer, poderosamente, para melhorar as condições de vida e de trabalho da população rural. (Ibidem, p. 214)

Os propósitos que orientaram a iniciativa já se encontravam explícitos no relatório apresentado ao secretário do Interior, no ano anterior, quando, reassumindo o comando da Diretoria Geral da Instrução Pública, Thompson afirmava o seu compromisso de reorientar o ensino no estado de São Paulo, segundo os princípios da Escola Nova. Tal reorientação implicava em colocar as questôes referentes à saúde em primeiro plano, pois, segundo afirmava:

a escola nova, como primeira das condições de eficiência educativa, que lhe compete, no preparo e formação de um indivíduo feliz, deve cuidar da sua personalidade física. Mas não basta conservar sã a parte somática do educando - importa mais curar o que a tem imperfeita ou apresenta tendências para a imperfeição.

Infelizmente, o papel da atual escola, no que diz de perto com a sua função sanitária, não é ainda tão amplo como houvera mister. Urge, pois, sejam abandonados os estreitos moldes da higiene escolástica vigente e substituída a família nos cuidados com a saúde das crianças [...]

A saúde física será, pois, uma das preocupações da escola nova, que empresta da antiga civilização grega o velho lema - mens sana in corpore sano - para seu lábaro. (Annuario do Ensino do Estado de São Paulo, 1917, p. 25-26)

Tais representações sobre o papel da escola na constituição de um indivíduo saudável e bem conformado fisicamente, por meio da preservação da saúde e da prevenção de doenças, certamente, presidiram a iniciativa de convocar os diretores

vida pela saúde corporal" (Ibidem, p. 745). Os inspetores não deixaram de assinalar a necessidade do aumento do número de postos médicos e da nomeação de médicos que se dedicassem à inspeção das escolas, medicando as crianças doentes e aconselhando os pais. 
dos estabelecimentos públicos de ensino para um curso de higiene elementar. Assim, durante 15 dias, os diretores que acorreram à capital paulista estiveram intensamente envolvidos em um conjunto de atividades organizadas em três modalidades: expositiva, prática e recreativa. O programa, que incidia sobre aspectos ligados às moléstias que infestavam a população das zonas rurais e sobre os mecanismos por meio dos quais se dava a sua transmissão, além de questôes referentes à água e ao saneamento, permitiu aos diretores ter contato com reconhecidas autoridades nos temas em pauta e percorrer laboratórios e institutos do Serviço Sanitário, hospitais, matadouro e estação de tratamento de água.

A iniciativa foi saudada pelas autoridades de ensino, como se pode observar nas anotações do inspetor escolar Benedicto Tolosa, que ressaltava a contribuição que poderiam oferecer à obra de saneamento os professores, munidos dos "ensinamentos úteis e práticos sobre as transmissões de moléstias [...] e sobre a água e as instalações sanitárias" (Annuario do Ensino do Estado de São Paulo, 1918, p. 748), adquiridos no curso oferecido pelo Butantã. Ensinamentos que viriam potencializar a atuação da escola, na medida em que:

Os conhecimentos e a prática de higiene pública, particular e profissional, que a escola pode fornecer e despertar entre as populações pertencentes a seu raio de ação, muito poderão concorrer para o saneamento das localidades, para aumentar a saúde dos indivíduos.

E nós sabemos que tudo isso levará a coragem a tantos lares minados por moléstias curáveis ou evitáveis, e o amor ao trabalho, a luta pela vida em todas as suas modalidades, atestarão os brilhantes frutos dessa campanha regeneradora e altamente patriótica a que está utilmente associada a escola pública primária. (Ibidem, p. 749)

$\mathrm{Na}$ mesma direção caminhavam as ponderações do inspetor Maurício de Camargo, que assinalava a cadeia que se poderia formar a partir da escola, possibilitando que as crianças tivessem uma participação ativa na difusão dos preceitos higiênicos no ambiente familiar, pois, segundo sentenciava: "Eduque-se a criança que ela será a educadora de seus pais" (Ibidem, p. 774). Compartilhava de posição semelhante o inspetor Julio Pestana, que assinalava o importante papel que cabia à escola na difusão dos ensinamentos de higiene, colaborando, ademais, para combater os preconceitos, as superstiçóes, a crença em simpatias e as práticas de cura não autorizadas pela Medicina, além de vícios como o alcoolismo e o tabagismo. Assim, a escola teria uma contribuição decisiva na difusão de noções de higiene às crianças; noções essas que, impressionando-as, seriam transmitidas por elas a suas famílias, contribuindo, destarte, para a preservação da saúde e para o saneamento do Brasil. 
Destacando o acerto da iniciativa de oferecer um curso de higiene elementar aos diretores de grupos, o inspetor escolar Helio Penteado de Castro sugeria que, no futuro, fossem lembrados os mestres distritais e rurais e instituída uma cadeira de Higiene nas escolas normais, de modo a preparar os professores em exercício, assim como os futuros professores, para ensinar às crianças os modos de prevenir as doenças mais comuns, por meio da aquisição de hábitos de vida saudáveis. No discurso dos inspetores escolares, a difusão dos preceitos higiênicos mesclava-se à urgência de uma educação cívica capaz de abrasileirar os estrangeiros, mas também os nacionais, dentre os quais se destacava a figura do caboclo.

Ao final do curso, o diretor do grupo escolar de Jacareí, Augusto Ribeiro de Carvalho, proferiu um discurso, que parece sintetizar os dois pilares em torno dos quais se articulavam as açôes da Diretoria Geral da Instrução Pública, relatadas por Thompson: a educação e a saúde. Segundo assinala Carvalho (Annuario do Ensino do Estado de São Paulo, 1918, p. 227)

$\mathrm{Na}$ instrução e na higiene, reside a grandeza futura de nossa Pátria.

Que não ouçamos mais as afirmações de que "o Brasil é um imenso hospital", ou de, nele, "tudo é grande, menos o homem".

O mestre pratica e propaga a higiene do corpo, da alma e do espírito. [...]

A Nação - o Estado - têm sede, não só do "ler", mas de todos os assuntos educativos e profissionais que hoje elevam a instrução a uma verdadeira "reformação social". [...]

Assim compreendida, inspiradora das regras de vida racional, tanto da vida individual, como da vida social - a higiene nos surge, realmente, como a ciência da vida.

Encarada na sua aplicação - a higiene tem um duplo objetivo: - a educação do indivíduo e a sua proteção contra as causas de moléstias, contra as incursões de agentes patogênicos..

Entusiasmado com o que aprendera, o diretor de escola alistava-se entre aqueles que acreditavam na urgente necessidade de uma reforma social, concebida como reforma dos costumes, a qual, pautada nos princípios da higiene, viesse a oferecer às crianças "regras de vida racional". Alçando a instrução e a higiene ao estatuto de pilares da obra de constituição da nação, o educador defendia a necessidade de mudança dos programas escolares, de modo que a higiene viesse a tornar-se parte fundamental do ensino elementar; solução essa que, no futuro, afastaria o Brasil do epíteto de "vasto hospital" que pesava sobre ele. Combate ao analfabetismo e saneamento articulavam-se nas ações da Diretoria Geral da Instrução Pública, como no discurso proferido pelo educador. 
Como parte das solenidades de encerramento do curso, Oscar Thompson fez uso da palavra, procurando realçar o importante papel que cabia aos diretores que frequentaram o curso, podendo a sua atuação contribuir para o "rejuvenescimento físico e moral do povo brasileiro" ou, ao contrário, ainda que inconscientemente, para a "degenerescência física e moral de nossos compatriotas" (Ibidem, p. 230), na medida em que a eles caberia doravante a responsabilidade por orientar os professores na obra de difusão dos preceitos higiênicos, bem como dos conhecimentos acerca dos agentes responsáveis pelas doenças.

O mesmo tom entusiástico com que conclamara os educadores paulistas à obra de combate ao analfabetismo perpassa o discurso proferido nessa ocasião, cujo mote é o saneamento do país: "não podeis negar o vosso apoio, franco e decidido, à maior obra que, neste momento a Pátria reclama de todos nós, o saneamento do solo, e, portanto, a extinção de moléstias que tornam os nossos patrícios inaptos para o progresso desta grande terra" (Ibidem, p. 231). Segundo ele, os resultados não se fariam esperar e traduzir-se-iam na transformação do Brasil de um "vasto hospital" em "um país de gente forte, sadia e bonita" (Ibidem, p. 234), um país povoado de bons cidadãos. A temática da formação do cidadão é abordada em conferência encomendada por Thompson a Sampaio Dória, que trata de recordar aos diretores os deveres do cidadão para com a pátria, dentre os quais o de preparar os seus futuros defensores, por meio da constituição do "homem sadio, o homem forte, a saúde e o vigor do corpo e do espírito" (Ibidem, p. 237), conquistados por meio da higiene e da ginástica.

Dirigindo-se aos diretores dos grupos escolares, em uma cerimônia oficial de encerramento do curso que atraíra para a capital paulista profissionais oriundos de diversas regiōes do estado, os discursos de Thompson e Sampaio Dória chamam a atenção pelas polaridades em torno das quais se articulam. Não parece casual, nesse sentido, que o mesmo tom empregado nas indagaçôes lançadas por Thompson em relação ao problema do analfabetismo e na resposta oferecida por Dória marque os discursos proferidos nessa ocasião solene. Empenhados em um projeto de constituição da nação em que a educação e a saúde assumiam lugar de destaque, configurando-se em instrumentos de regeneração da população, as autoridades procuravam, em seus discursos, apresentar como legítimo o projeto de nação pelo qual se batiam, numa operação que visava silenciar outros projetos, relegando-os ao lugar da ignorância e da degenerescência.

\section{A educação higiênica em palavras e imagens}

O projeto de formação de homens fortes, saudáveis e vigorosos encontrou na publicação de pequenos livros e cartilhas de higiene um importante recurso pedagógico, cuja elaboração envolveu médicos, professores, editores e ilustradores. 
Manuais escolares pequenos, elaborados segundo um formato editorial no qual textos breves se associam a gravuras, constituíram-se em alguns dos dispositivos por meio dos quais se procurou pôr em circulação, no âmbito da escola, um amplo rol de preceitos higiênicos, cuja aquisição deveria culminar numa vida saudável e civilizada.

Movido pelo propósito de difundir os preceitos higiênicos na escola primária, Antonio de Almeida Junior, médico e professor da Escola Normal do Brás, publicou em 1923, pela Editora Monteiro Lobato, mais tarde Companhia Editora Nacional, a Cartilha de hygiene, obra ilustrada por Belmonte ${ }^{15}$ e destinada às crianças e a seus mestres. Os objetivos que orientaram a iniciativa podem ser lidos na epígrafe do texto destinado aos professores, que abre a obra: "criança deve ser tão instruída em higiene como em língua pátria ou em números" (Almeida Junior, 1936, p. 3). O texto "Educação higiênica", espaço de diálogo com o professor, por intermédio do qual o autor procura orientar a sua atuação docente, deixa claro o caráter prático do trabalho que deveria ser desenvolvido com vistas a inculcar nas crianças "hábitos úteis, referentes ao asseio, à alimentação, ao exercício" (Ibidem, p. 3).

Dentre as lições que compõem a Cartilha, três sequências de quadrinhos permitem sintetizar os temas e os modos como eles são abordados por Almeida Junior. Na primeira, intitulada "Oito regras de ouro", um menino encena uma sequência de gestos cotidianos, modulados segundo os preceitos higiênicos. $\mathrm{O}$ sono, o banho diário, a escovação dos dentes, a alimentação, o consumo de água, as brincadeiras ao ar livre e a evacuação são tematizados nos oito quadrinhos em que se representam as condutas do menino asseado. $\mathrm{O}$ ambiente à sua volta, sempre limpo, arejado e bem arranjado, não deixa dúvidas quanto à presença da mãe zelosa e à harmonia familiar. Limpeza, felicidade, decência e harmonia são alguns dos valores que emergem das gravuras, arranjadas como num filme. Um detalhe curioso é a presença do Saci-pererê, personagem lendário do folclore brasileiro que, ao longo das lições, acompanha o menino, sempre apoiando os bons hábitos e, por vezes, censurando os deslizes ${ }^{16}$.

I5 Belmonte é o nome artístico do ilustrador, caricaturista, pintor, jornalista e escritor paulistano Benedito de Barros Barreto. Considerado como o cronista da política brasileira dos anos 1920 aos 1940, Belmonte nasceu em 15/5/I 896 e morreu em 19/4/I 947. Ilustrou livros de Monteiro Lobato, dentre os quais Emília no país da gramática, em 1934, e foi o criador do personagem Juca Pato, por meio do qual fazia críticas à elevação de preços, ao arrocho salarial e à corrupção na política. Em parceria com Lobato, deu corpo ao Jeca Tatu.

I6 Ver, a esse respeito, Rocha (2003a e 2003b). 


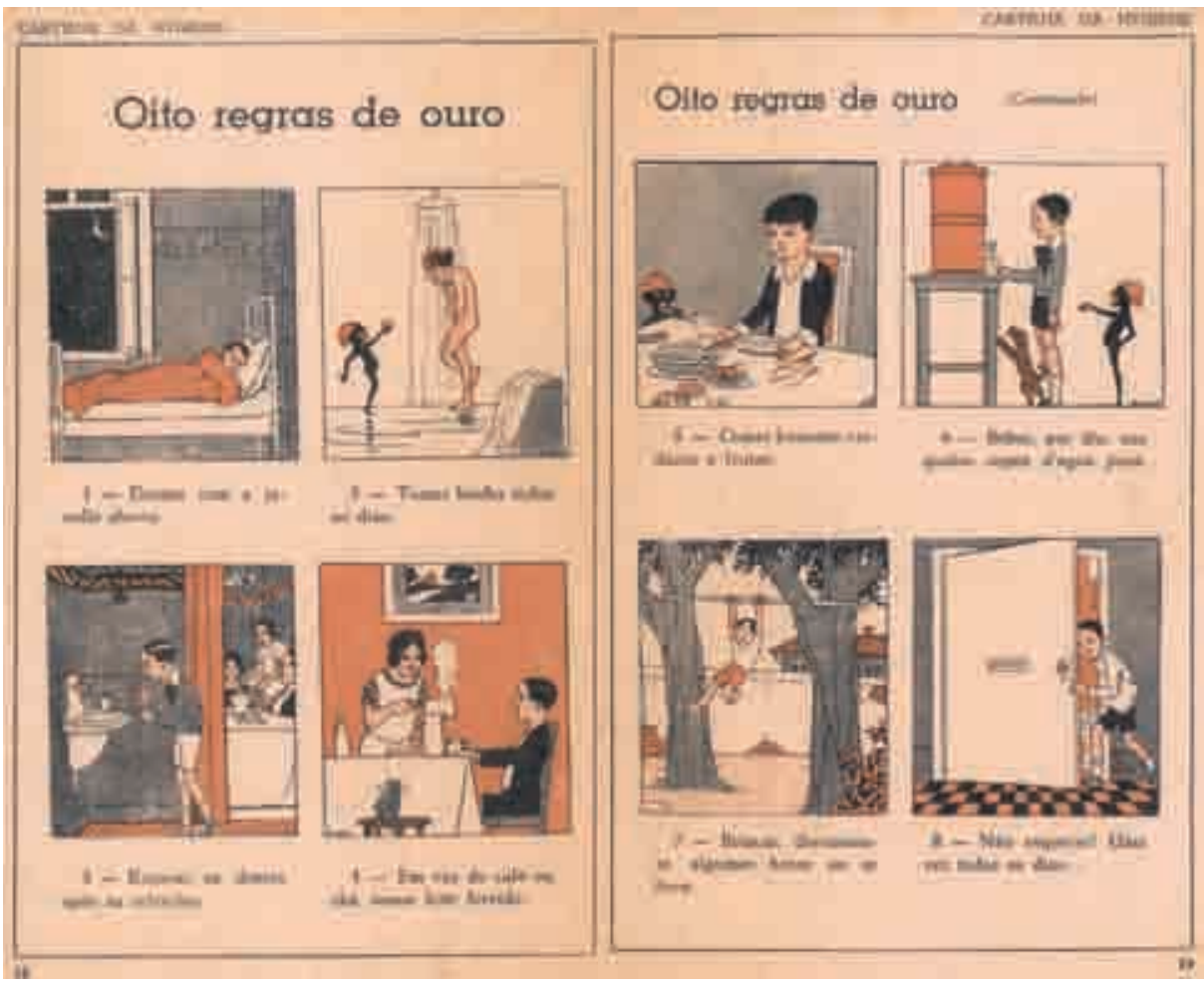

Imagem I: Lições da Cartilha de hygiene, de autoria de Almeida Junior, 1936. Fonte: Biblioteca do Centro do Professorado Paulista.

A segunda sequência encena a "História de um beberrão", em oito quadrinhos. Da família feliz, reunida em um ambiente doméstico modesto, onde o pai mima os seus pequenos, enquanto a esposa serve a mesa, o alcoólatra é conduzido a uma tragédia, cujo primeiro ato põe em cena as "más companhias", em torno da mesa de um bar, para desdobrar-se em cenas de violência doméstica, crime, prisão, enlouquecimento e morte. Tudo isso narrado como uma desgraça que, de um lado, conduz o alcoólatra à morte e, de outro, lança a família à miséria, representada pela imagem da mãe e seus pequenos, todos maltrapilhos, sentados no chão, implorando pela caridade dos que passam.

Como na "História de um beberrão", são os hábitos considerados perniciosos que ocupam o centro da cena da sequência de quadrinhos intitulada "Como se fica tuberculoso". Em contraste com o cenário harmônico no qual se encenam as "Oito regras de ouro", aqui a escassez de alimentos, o amontoamento de pessoas, o álcool, a sujeira e as moscas se articulam para compor o quadro de predisposição à tuberculose. A expressão alegre e descontraída do menino cede lugar ao ar 


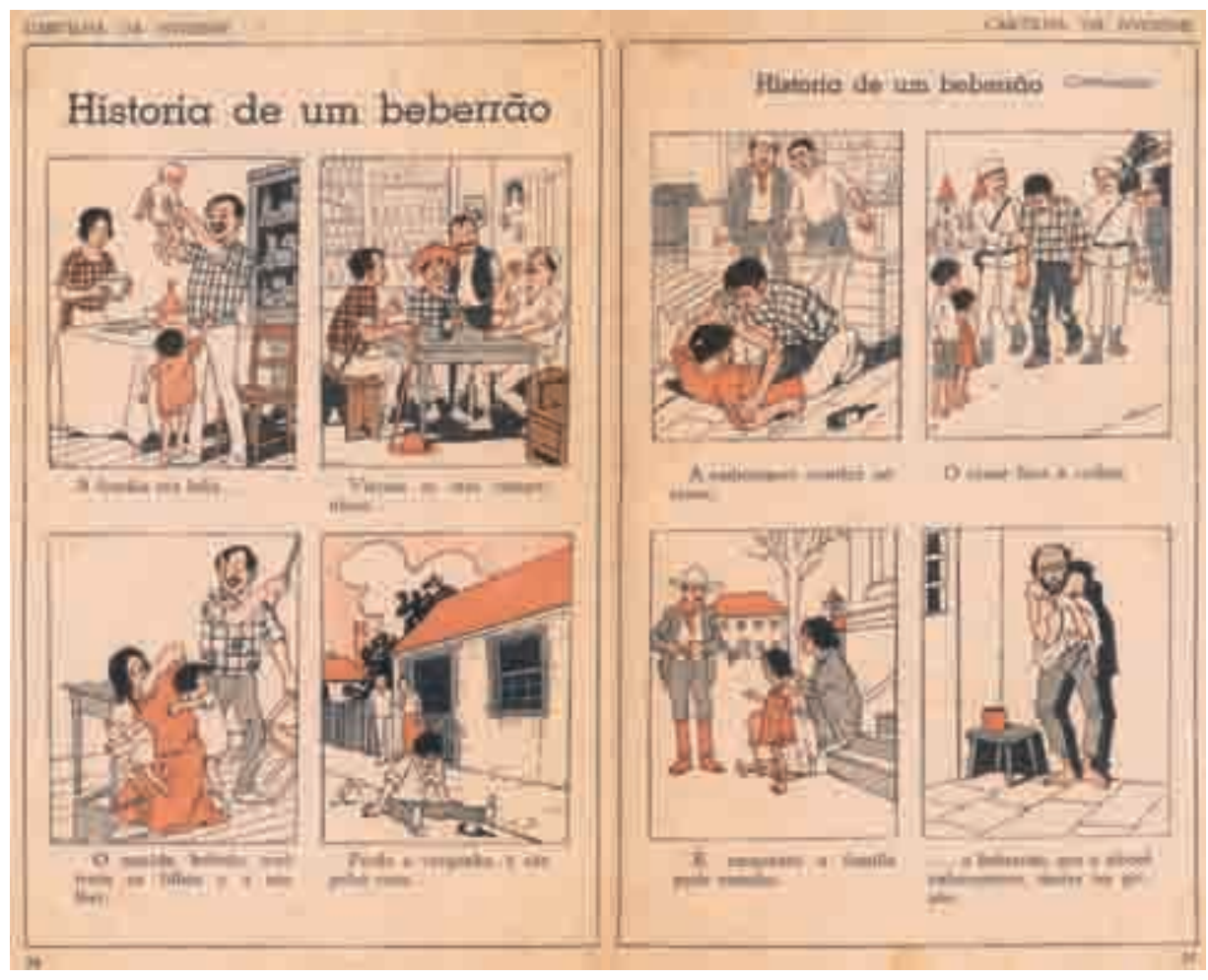

Imagem 2: Lições da Cartilha de hygiene, de autoria de Almeida Junior, 1936.

Fonte: Biblioteca do Centro do Professorado Paulista.

cadavérico e depauperado de crianças e adultos, a prenunciar as desgraças futuras. Algumas das legendas que acompanham os quadrinhos chamam a atenção pelo modo irônico como abordam os cuidados que deveriam ser tomados para evitar a doença, seguindo o tom do próprio título da lição. Dentre eles, destaca-se o texto que acompanha a imagem das pessoas dividindo um mesmo leito, "muita gente num quarto sem ar e sem asseio: bom caminho para a tuberculose". No mesmo tom, a legenda do último quadrinho, no qual figura uma vaca esquálida, anuncia: "uma vaca tuberculosa. Beba o leite dela, sem ferver, se quer ficar tuberculoso" (Ibidem, p. 30-31).

Ocupando lugar de destaque no projeto de educação higiênica da criança e, por meio desta, dos adultos à sua volta, as imagens materializam o programa educativo no qual se inscrevem, tornando legíveis as representações sobre a população pobre e seus hábitos em que tais imagens se pautam. A narrativa visual que compõem, na qual os enunciados ganham, em geral, o papel de legendas, possibilita ler os objetivos a que respondem as intervençôes sobre a população, desenhadas a par 
da atuação da Diretoria Geral da Instrução Pública, sobretudo a partir da segunda gestão de Oscar Thompson.

Encenando as prescrições higiênicas e os interditos sobre as práticas cotidianas de cuidado com o asseio do corpo e do meio, as imagens podem ser lidas como dispositivos políticos e pedagógicos de disciplinarização. Dispositivos esses que tornam visível um conjunto de representaçoes, em circulação no período, sobre os modos de viver da população pobre, em sua contraposição a uma vida regrada segundo os princípios da ciência. Nessa pedagogia da boa saúde, que orienta o programa visual materializado em obras como a de Almeida Junior, comparecem, nesse sentido, temas como as relações familiares, os modos de criação das crianças, a habitação, o corpo, a saúde, a doença e a vida.

Duas meninas e um menino sorridentes, bem nutridos, limpos, bem vestidos e penteados, representam os "três irmãos bem educados" que introduzem as crianças nas páginas da homônima Cartilha de higiene, publicada na década de 1930, pelo médico Renato Kehl, com ilustrações de Acquarone. ${ }^{17}$ Dirigindo-se aos professores, o autor apresenta o pequeno livro como um "guia para o ensino sugestivo e persuasivo de noções elementares condizentes com a preservação da saúde” (Kehl, s.d., n.p.). A estrutura da obra, composta, como assinala Kehl, por muitas figuras intercaladas a preceitos "claros, curtos e incisivos" (Ibidem, n.p.), justificava-se em função do que o autor considerava como características naturais da infância: o interesse das crianças pelo que lhes agrada e a aceitação daquilo que compreendem. Modelos de comportamento exemplar, os três irmãos são apresentados ao leitor por meio de uma minuciosa narrativa que recobre os seus gestos cotidianos, desde o amanhecer até a hora de recolher-se.

A Cartilha de higiene de Kehl constitui-se em um catálogo de preceitos higiênicos organizados de A a Z: o A desdobra-se em três liçôes que versam sobre o ar, a água e os alimentos; o B tematiza o banho; o C, a casa; o D, os dentes; e assim sucessivamente. Como nas cartilhas produzidas com o objetivo de ensinar as crianças a ler, as lições são encabeçadas pela letra, disposta ao lado de uma ilustração do tema a ser trabalhado. Abaixo, o título, seguido de um texto - acompanhado, em geral, de uma outra ilustração. $\mathrm{O} B$ ensina sobre o banho, contendo ilustrações do banho de mar e do banho de chuveiro, as quais se articulam com o texto que preceitua:

Um banho todos os dias.

Depois do banho enxugue-se bem.

Quem não tem banheiro toma banho numa bacia ou mesmo numa tina, mas não deixa, por isto, de lavar o corpo.

17 Francisco Acquarone (1898-1954) trabalhou como jornalista e ilustrador do periódico Dom Quixote, a partir de 1918, e colaborou com ilustrações em periódicos como O Jornal, A Noite e Dom Casmurro. 
A água e o sabão não fazem mal a ninguém.

Os banhos de mar são saudáveis quando não muito demorados.

Ficar na praia e na água muitas horas é um perigo para a saúde.

Trazer o corpo asseado é sinal de inteligência e boa educação. (Ibidem, p. 18)

Higiene e boa educação compõem os pilares da proposta de educação higiênica que atravessa esse abecedário de bons hábitos, organizado segundo o objetivo de incutir nas crianças modos de viver e de comportar-se. Nas entrelinhas, o texto indicia que a pobreza não justifica a negligência com o asseio. Na falta de banheiro, uma bacia ou uma tina seriam suficientes para garantir o banho diário.

$\mathrm{O} \mathrm{H}$ apresenta os hábitos ou, segundo indica a observação entre parênteses, os bons hábitos como: lavar as mãos, escovar as unhas, lavar a cabeça, pentear os cabelos, manter uma postura ereta, dentre outros. Paralelamente a isso, o M serve de espaço para a reprovação aos maus hábitos, por meio de ilustrações que, em sua articulação com o texto, apresentam crianças de semblantes descuidados e expressōes repugnantes, encenando gestos como cuspir no chão; espirrar lançando jatos de saliva, ainda que com um lenço na mão; e roer as unhas.

Para concluir, a última lição é um convite à adesão ao código de bons hábitos, exemplarmente ilustrado pelas virtudes higiênicas dos três irmãos, Xisto, Yolanda e Zenaide:

Quem quer se parecer com os três irmãos?

- Nada mais fácil. Basta seguir os conselhos deste livrinho. Quem o fizer, tornar-se-á logo uma criança forte e bonita.

- Não se esqueça de que não há felicidade sem saúde e só se pode conservá-la vivendo hi-gi-e-ni-ca-men-te.

(Ibidem, p. 48)

Novamente aqui, saúde, beleza, força e felicidade emergem como consequências de uma vida modulada pela obediência às regras ditadas pela higiene, contrapondose às tristes consequências de uma vida considerada desregrada, representada pela falta de asseio das mãos, das unhas, dos cabelos, dos dentes; por uma alimentação inadequada; pelos deslizes em relação à limpeza da casa, dentre tantos outros. Nesse jogo de oposiçóes entre o comportamento exemplar e as atitudes que se busca configurar como desregramentos, torna-se explícito o intento de remodelar os gestos infantis, transformando em hábitos os gestos exemplares, encenados nas imagens e enunciados nos pequenos textos. O desvio e a regra articulam-se, nesse sentido, como confirmação de um comportamento higiênico que se procura configurar como norma. 


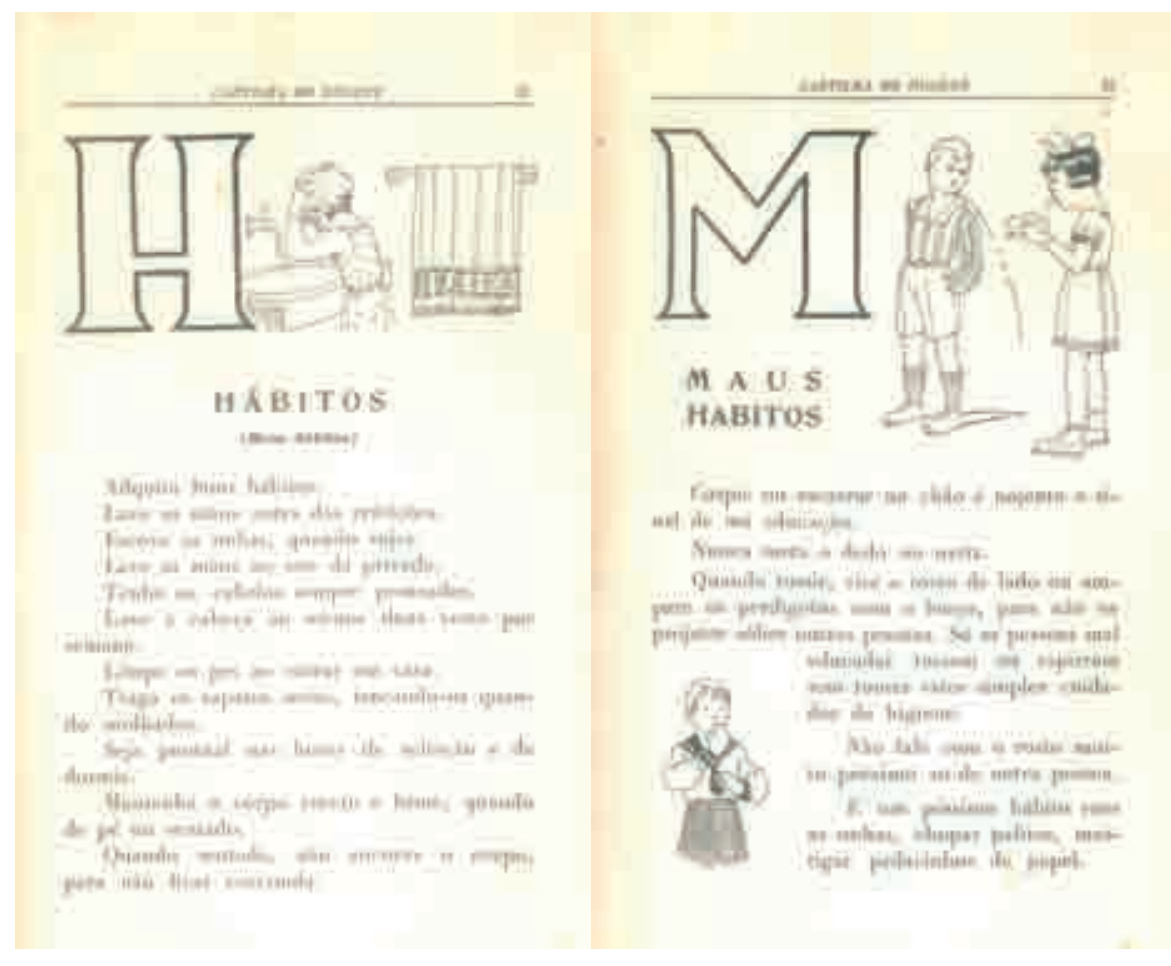

Imagem 3: Lições da Cartilha de higiene, de Renato Kehl, s.d. Fonte: CRE Mário Covas.

O intento de incutir nas crianças os sãos principios da Higiene orientou também a iniciativa da professora Sara Sampaio Arruda. Experimentada nas lides do magistério, a professora publicou, em 1927, o livro Rimas para a infância, reunindo uma coleção de poemas sobre higiene. Aplaudido pela imprensa, que lhe dedicou os mais entusiásticos comentários, o livro traz como epígrafe a afirmação de Belisário Pena: "sanear o Brasil é povoá-lo, é enriquecê-lo, é moralizá-lo" (Arruda, 1927, n.p.). Nas palavras dedicadas aos colegas professores, Arruda sugere que a pauta musical anexada ao final do livro fosse utilizada para transformar os versos em canções, podendo o livro, desse modo, subsidiar o trabalho não apenas nas aulas de Higiene, mas também nas atividades de música, declamação e leitura suplementar. Os resultados positivos eram assegurados pela autora, que já experimentava o método de inculcação de hábitos higiênicos por meio de rimas em suas próprias aulas, nos mais de 12 anos de exercício profissional.

Imagens acompanhadas de pequenos poemas compõem o guia de bons hábitos, que tematiza o asseio das mãos, das unhas, dos dentes; o uso do lenço; o banho diário; as práticas de alimentação; os modos de comportar-se nas ruas. A ilustração de uma menina de perfil, tesoura em punho, cortando as unhas, introduz o poema "As unhas": 
Unhas limpas, aparadas;

Ouçam, pois, os meus conselhos:

Tragam-nas mui bem tratadas

Desde o mínimo aos artelhos.

Minhas unhas, que cuidado!

São polidas, são brilhantes:

Meus dedinhos afilados

São todos interessantes!

Unhas compridas, afiadas,

Pretinhas, de luto e sujas,

Das meninas descuidadas...

Mais parecem de corujas!

(Ibidem, p. 15)

Rimando "aparadas" e "bem tratadas", "brilhantes" e "interessantes", em contraposição a "afiadas" e "descuidadas", "sujas" e "corujas", a autora constrói, num mesmo poema, a oposição entre os bons e os maus hábitos, a limpeza e a sujeira, o cuidado e o desmazelo. As oposições entre vícios e virtudes também marcam a construção do poema “Que vício!”, ilustrado por uma imagem que teve ampla circulação nas campanhas sanitárias empreendidas em São Paulo, na segunda metade da década de 1920, as quais se pautavam na afirmação da necessidade de produção de uma "consciência sanitária individual"18. A imagem é de um homem simples, modesto, em trajes rústicos usados predominantemente nos meios rurais. Representando o brasileiro miscigenado, o qual, segundo se propalava à época, poderia ser redimido de todos os seus vícios, por meio da educação e da higiene, o homem cospe no chão. Na página ao lado, o poema condena a reprovável atitude:

É um crime cuspir no chão!

E merece uma censura

O maldoso cidadão

Que pratica tal feiúra...

Os velhos mal educados

Procedem dessa maneira;

Maníacos e atrasados,

Insistem na grande asneira.

A sã meninada de hoje

É sabichona, adiantada,

De todos os males foge,

Não há de crescer viciada! (Ibidem, p. 31)

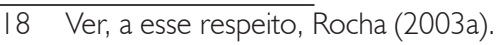




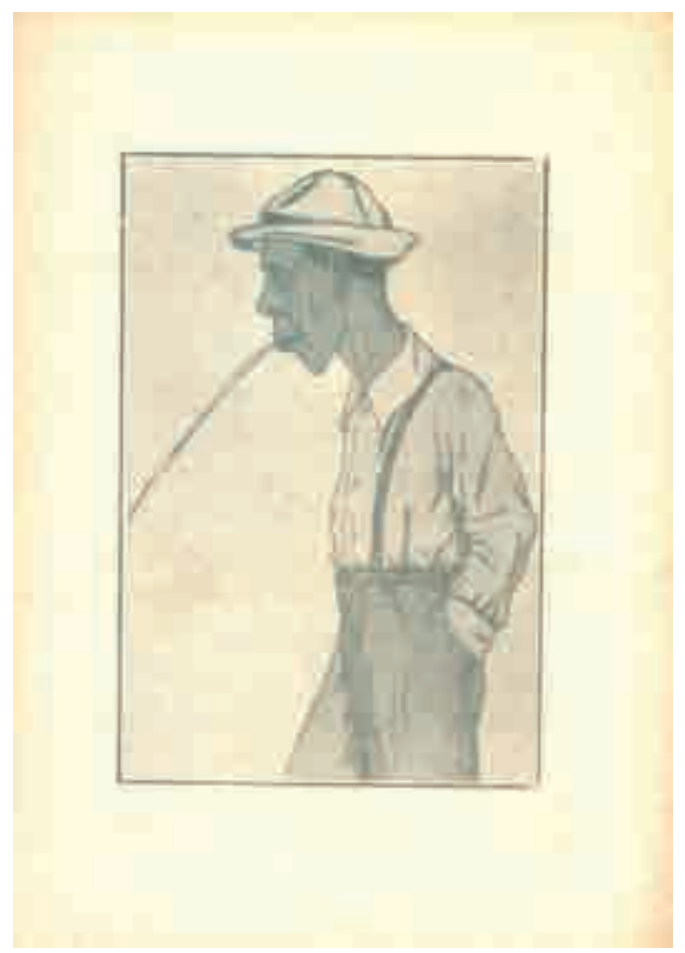

Imagem 4: Lição de Rimas para a infância, de autoria de Sara Arruda, 1927. Fonte: Biblioteca do Centro do Professorado Paulista.

Vícios e virtudes, atraso e progresso, "velhos mal educados" e "sã meninada de hoje" opõem-se, no jogo de antíteses com que se tece o poema da professora, em sintonia com a retórica presente nos discursos do período. O feio, o maníaco, o atrasado e o mal-educado condensados na figura do brasileiro, com seus hábitos viciosos, cedem espaço à promessa de um futuro glorioso, em que o país emerge, como na epígrafe do livro, saneado, rico e moralizado. Crianças "sabichonas" e "adiantadas" metaforizam a promessa de um país redimido do analfabetismo, da doença e da pecha de anomia que pairava sobre a população.

Como no livro da professora e nos dos médicos ou, ainda, como nos discursos dos educadores investidos nos altos cargos da instrução pública, a doença, a sujeira, o analfabetismo e os comportamentos desregrados combinam-se na imagem do mau garoto, estampada em um livro de leitura aprovado e adotado pela Diretoria Geral da Instrução Pública de São Paulo, sob o título Espelho. A gravura, a bico de pena, póe em cena um menino de pés descalços a perseguir um animal, sob o olhar reprovador da mãe, enquanto o pequeno texto confirma os dissabores gerados pelas atitudes do pequeno. 


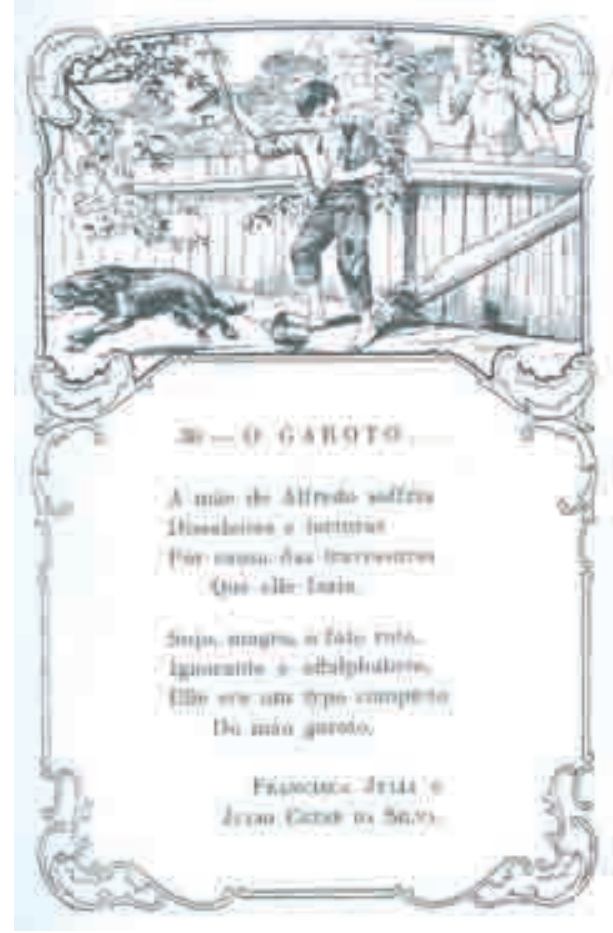

Imagem 5: Lição do livro de leitura Espelho, de Thales de Andrade, s. d.

Fonte: Biblioteca do Centro do Professorado Paulista

Nos livros de leitura, assim como nas cartilhas, nos livros infantis e nas edições voltadas para um público mais amplo ${ }^{19}$, a retórica da saúde e da educação ganha um espaço importante, na década de 1920, oferecendo às crianças das escolas primárias um guia de vida, configurado segundo os imperativos da higiene. Palavras e imagens que encenam a regra e as reprováveis transgressóes articulam-se, procurando inscrever a vida cotidiana em práticas de cuidado com o corpo, com a roupa e com o ambiente doméstico. A reforma de costumes em que se inscreve a produção de manuais escolares, como as cartilhas dos médicos Almeida Junior e Kehl, o livro de poemas da professora Arruda, ou mesmo livros de leitura, como o de Andrade, não incidia, entretanto, apenas sobre as crianças. A leitura dos textos e das imagens deixa entrever a intenção aí presente de atingir, por meio das crianças, as suas famílias, inscrevendo-as em um cotidiano civilizado, materializando a promessa de redenção do Brasil pela educação e pela saúde, propalada igualmente nos discursos e nas iniciativas de Oscar Thompson e Sampaio Dória. Promessa,

19 Sobre essas edições, ver Magalhães e Rocha (2009). 
aliás, recorrente no discurso dos nossos intelectuais que, em suas ambições de alçar o Brasil ao nível dos países considerados civilizados, têm-se visto, historicamente, às voltas com o fantasma da degenerescência do povo.

\section{Referências bibliográficas}

ALMEIDA JUNIOR, A. O saneamento pela educação. These defendida perante a Faculdade de Medicina de São Paulo, a 15 de março de 1922.

ALMEIDA JUNIOR, A. Cartilha de hygiene. 15. ed. São Paulo: Companhia Editora Nacional, 1936.

ANDRADE, T. Espelho: $1^{\circ}$. livro de leitura. São Paulo: Companhia Editora Nacional, s.d.

ANNUARIO do Ensino do Estado de São Paulo, 1909-1910, 1917, 1918, 1920-1921.

ANTUNHA, H. C. G. A instrução pública no Estado de São Paulo: a Reforma de 1920. São Paulo: FE-USP, 1976. (Col. Estudos e Documentos, v. 12).

ARRUDA, S. S. Rimas para a infância. São Paulo: Liberdade, 1927.

CARVALHO, M. M. C. Quando a história da educação é a história da disciplina e da higienização das pessoas. In: FREITAS, M. C. (Org.) História social da infância no Brasil. São Paulo: Cortez; Bragança Paulista: Edusf, 1997.

CARVALHO, M. M. C. Molde nacional e forrma civica: higiene, moral e trabalho no projeto da Associação Brasileira de Educação (1924-1931). Bragança Paulista-SP: Edusf, 1998.

CARVALHO, M. M. C. Antônio de Sampaio Dória. In: FÁVERO, M. L. A.; BRITTO, J. M. (Org.). Dicionário de educadores no Brasil: da Colônia aos dias atuais. Rio de Janeiro: Editora UFRJ; MEC-INEP, 1999.

KEHL, R. Cartilha de higiene: alfabeto da saúde. Rio de Janeiro: Francisco Alves, s.d.

NAGLE, J. Educação e sociedade na Primeira República. 2. ed. Rio de Janeiro: DP\&A, 2001.

RIBEIRO, M. A. R. História sem fim... Inventário da saúde pública. São Paulo: Editora da Unesp, 1993.

ROCHA, H. H. P. Imagens do analfabetismo: a educação na perspectiva do olhar médico no Brasil dos anos 20. 1995. Dissertação (Mestrado em Educação) - Faculdade de Educação, Unicamp, Campinas.

ROCHA, H. H. P. Higiene em imagens: os impressos e a propaganda de novos modos de viver. Revista Portuguesa de Pedagogia, Coimbra, v. 37, n. 2, p. 185-201, 2003a.

ROCHA, H. H. P. A higienização dos costumes: educação escolar e saúde no projeto do Instituto de Hygiene de São Paulo (1918-1925). Campinas: Mercado de Letras; São Paulo: Fapesp, 2003b. 